\title{
Patterned Functional Arrays by Selective De-Wetting
}

HONGYOU FAN, DHAVAL DOSHI, YUNFENG LU, and C. JEFFREY BRINKER

The University of New Mexico/NSF Center for Micro-Engineered Materials, The Advanced Materials Laboratory, 1001 University Blvd, NM 87106, Sandia National Laboratories, Albuquerque, NM 87185.

\section{ABSTRACT}

Using a micro-Contact Printing $(\boldsymbol{\mu}-\boldsymbol{C P})$ technique, substrates are prepared with patterns of hydrophilic, hydroxyl-terminated SAMs and hydrophobic methyl-terminated SAMs. Beginning with a homogeneous solution of silica, surfactant, ethanol, water, and functional silane, preferential ethanol evaporation during dip-coating, causes water enrichment and selective de-wetting of the hydrophobic SAMs. Correspondingly, film deposition occurs exclusively on the patterned hydrophilic SAMs. In addition, by co-condensation of tetrafunctional silanes $\left(\mathrm{Si}(\mathrm{OR})_{4}\right)$ with tri-functional organosilanes $\left((\mathrm{RO})_{3} \mathrm{Si}\left(\mathrm{CH}_{2}\right)_{3} \mathrm{NH}_{2}\right)$, we have selectively derived the silica framework with functional amine $\mathrm{NH}_{2}$ groups. A pH sensitive, micro-fluidic system was formed by further conjugation reactions with $\mathrm{pH}$ sensitive dye molecules.

\section{INTRODUCTION}

Living systems exhibit form and function on multiple length scales, and the prospect of imparting life-like qualities to man-made materials has inspired many recent efforts to devise assembly strategies with hierarchical materials. For example, Yang et al. ${ }^{[1]}$ grew surfactanttemplated mesoporous silica on hydrophobic patterns prepared by micro-contact printing $\mu C P$. Trau et al. [2] formed oriented mesoporous silica patterns, using a micro-molding in capillaries MIMIC technique, while Yang et al.[3] combined MIMIC, polystyrene sphere templating, and surfactant-templating to create oxides with three levels of structural order. Overall, great progress has been made $t$ in controlling structure on scales ranging from several nanometers to several micrometers. However, the materials prepared have been limited to oxides with no specific functionality, whereas for many of the envisioned applications of hierarchical materials in micro-systems (such as sensors, waveguides, photonics, and electronics) it is necessary to define both form and function on several scales of length. In addition, the patterning strategies employed thus far require hours or even days for completion. Such slow processes are inherently difficult to implement in commercial environments.

In this report, we have combined evaporation-induced (silica/surfactant) self-assembly $(E I S A)[4,5]$ with dip-coating on micro-Contact Printed substrates to form patterned arrays in seconds. In addition, by co-condensation of tetrafunctional silanes ( $\left.\mathrm{Si}(\mathrm{OR})_{4}\right)$ with tri-functional organosilanes $\left((\mathrm{RO})_{3} \mathrm{Si}\left(\mathrm{CH}_{2}\right)_{3} \mathrm{NH}_{2}\right)$, we have selectively derivatized the silica framework with functional amine ligands. After reacting with $\mathrm{pH}$ sensitive dye molecules, we formed a $\mathrm{pH}$ sensitive micro-fluidic system.

\section{EXPERIMENTAL}

The A2** silica stock solution was prepared using a formula designed to minimize the siloxane condensation rate. A two-step acid catalyzed hydrolysis and condensation reaction was used to prepare the silicates sols.

(1).An A2** stock solution was prepared. It was composed of tetraethyl orthosilicate (TEOS), ethanol, deionized water, and $0.07 \mathrm{~N} \mathrm{HCl}$ which were mixed in a pyrex reaction kettle in the molar ration (TEOS) $1.0:(\mathrm{EtOH}) 3.8:\left(\mathrm{H}_{2} \mathrm{O}\right) 1.1:(\mathrm{HCl}) 5 \times 10^{-5}$ and refluxed at $60^{\circ} \mathrm{C}$ for 90 


\section{DISCLAIMER}

This report was prepared as an account of work sponsored by an agency of the United States Government. Neither the United States Government nor any agency thereof, nor any of their employees, make any warranty, express or implied, or assumes any legal liability or responsibility for the accuracy, completeness, or usefulness of any information, apparatus, product, or process disclosed, or represents that its use would not infringe privately owned rights. Reference herein to any specific commercial product, process, or service by trade name, trademark, manufacturer, or otherwise does not necessarily constitute or imply its endorsement, recommendation, or favoring by the United States Government or any agency thereof. The views and opinions of authors expressed herein do not necessarily state or reflect those of the United States Government or any agency thereof. 


\section{DISCLAIMER}

Portions of this document may be illegible in electronic image products. Images are produced from the best available original document. 
minutes. The resulting solution called the "A2** stock solution" was cooled to room temperature and stored at $-20^{\circ} \mathrm{C}$. This solution was stable in the freezer for a half year.

(2).A solution of silica sol with surfactants and functional organosilanes was prepared. In the second hydrolysis step, additional deionized water and $\mathrm{HCl}$ were added to make up the desired final molar ration. Organic functional silanes, $\left(R^{\prime}-\operatorname{Si}(O R)_{3}\right.$, (where $R^{\prime}$ is a non-hydrolyzable organic functional ligand) were added and then followed by surfactants. The final reactant molar ratios were: 1 TEOS : $22 \mathrm{C}_{2} \mathrm{H}_{5} \mathrm{OH}: 5 \mathrm{H}_{2} \mathrm{O}: 0.004 \mathrm{HCl}: 0.02-0.2$ surfactant : $0.039-0.8$ functional silanes. The surfactant templates were selectively removed by calcination in an inert atmosphere to a temperature sufficient to decompose the surfactant molecules $\left(e . g ., 350^{\circ} \mathrm{C}\right.$ for $\mathrm{CTAB}$ ) without degrading the covalently-bound organic ligands [6], or by solvent extraction with ethanol.

Dip-coating of patterned (hydrophilic/hydrophobic) substrates was performed at a withdrawal speed of $7.6-51 \mathrm{~cm} / \mathrm{min}$ under ambient laboratory conditions. Hydrophobic/ hydrophilic patterns were created by microcontact printing of self-assembled monolayers $S A M s$ on silicon or gold substrates, or by a technique involving electrochemical desorption of methylterminated SAMs from patterned gold electrodes followed by immersion in hydroxyl-terminated alkane thiols. The gold substrates were prepared by evaporation of $500 \mathrm{~nm}$ of gold (99.999\%) onto chromium-primed $(10 \AA)$ silicon wafers under vacuum. The silica wafer substrates were prepared by cleaning with piranha solution $\left(70 / 30 \mathrm{v} / \mathrm{v} \mathrm{H}_{2} \mathrm{SO}_{4} / 30 \% \mathrm{H}_{2} \mathrm{O}_{2}\right.$, which is a very dangerous process) for 30 minutes at $60^{\circ} \mathrm{C}$, and rinsing thoroughly with DI water.

\section{RESULTS AND DISCUSSION}

Polydimethylsiloxane (PDMS) stamps that have relief structures consisting of circles, triangles, and stripes were fabricated according to reports $[7,8]$. The stamp was first inked with a $1 \mathrm{mM}$ solution of $\mathrm{HS}\left(\mathrm{CH}_{2}\right)_{11} \mathrm{CH}_{3}$ in ethanol and dried in a nitrogen stream. The stamp was then put in contact with the surface of the gold substrate for 30 seconds. The hydrophobic thiolderived sample was then washed with a $10 \mathrm{mM}$ solution of $\mathrm{HS}\left(\mathrm{CH}_{2}\right)_{11} \mathrm{OH}$ in ethanol to passivate the remaining area that had not contacted the stamp. Subsequently, the sample was rinsed with ethanol several times, then dried under a flow of nitrogen. As for the patterning fabrication on a silica wafer or glass, hydrophobic organosilane, such as octadecyltrichlorosilane, was used in hexane or toluene at a concentration of $10 \mathrm{mM}$. After first printing the hydrophobic silane, the wafer was washed with hexane several times, dried in a nitrogen stream, and then placed in an $80^{\circ} \mathrm{C}$ oven to cure and promote siloxane condensation. In this case, the amorphous, hydroxylated silica surface itself serves as a hydrophilic pattern $\left(\mathrm{H}_{2} \mathrm{O}\right.$ contact angle less than $10^{\circ}$ ). Figure 1 shows the schematic process of forming of PDMS stamps and the patterned SAMs.

Pattern formation on hydrophilic/hydrophobic surfaces relies on the selective de-wetting of the hydrophilic coating precursor from the hydrophobic patterns. In order to demonstrate the de-wetting behavior on a stamped patterned surface, a patterned hydrophobic/hydrophilic gold substrate was immersed in a solution containing alcohol, water, and propylene glycol. During dip-coating, preferential alcohol evaporation enriched the depositing film in water and propylene glycol causing spontaneous de-wetting of the hydrophobic patterns. Figure 2 shows an optical image of the plan-view of the resulting surface after dip-coating in a water/propylene glycol/ethanol solution. Although the initial solution wets both the hydrophilic and hydrophobic regions, preferential evaporation of ethanol causes de-wetting of the hydrophobic regions causing the water/EG solution to reside exclusively on the hydrophilic regions. As shown, water only absorbs on the hydrophilic region. In addition, de-wetting occurs not only on stripes, but 
also on isolated circles. Propylene glycol was used to avoid inconvenient image taking because water evaporates quickly.

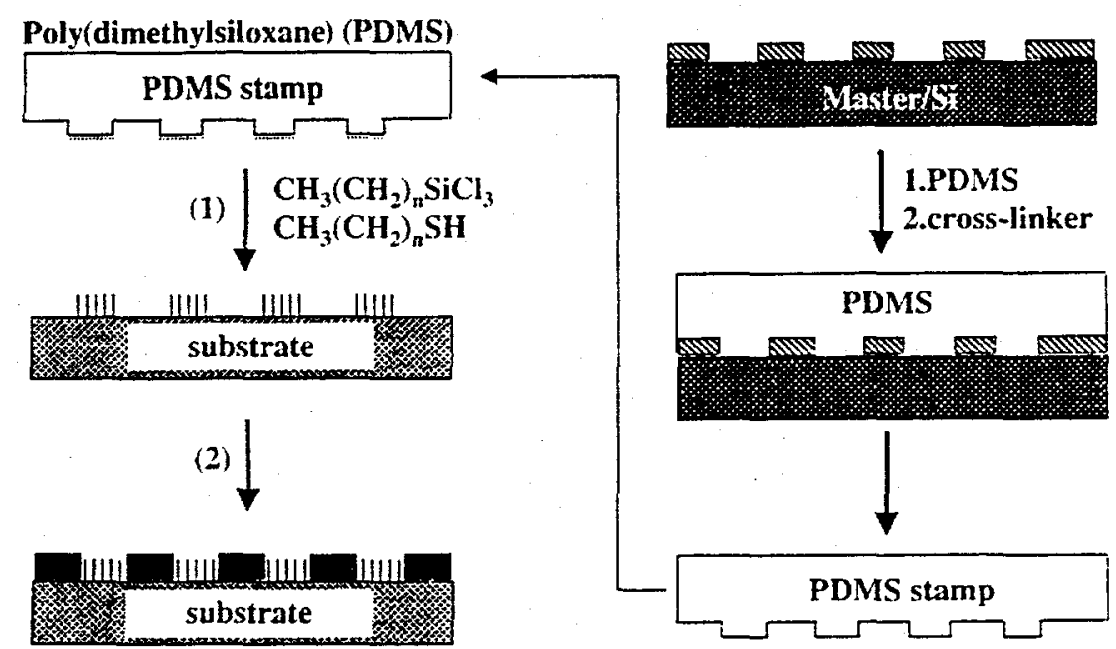

Figure 1. Scheme of making of PDMS stamp and fabrication of patterns on gold and silica surfaces. (1) Micro-contact printing: formation of hydrophobic and hydrophilic region (2) Dipcoating of sol-gel precursors including silica, surfactant, water, and alcohol.
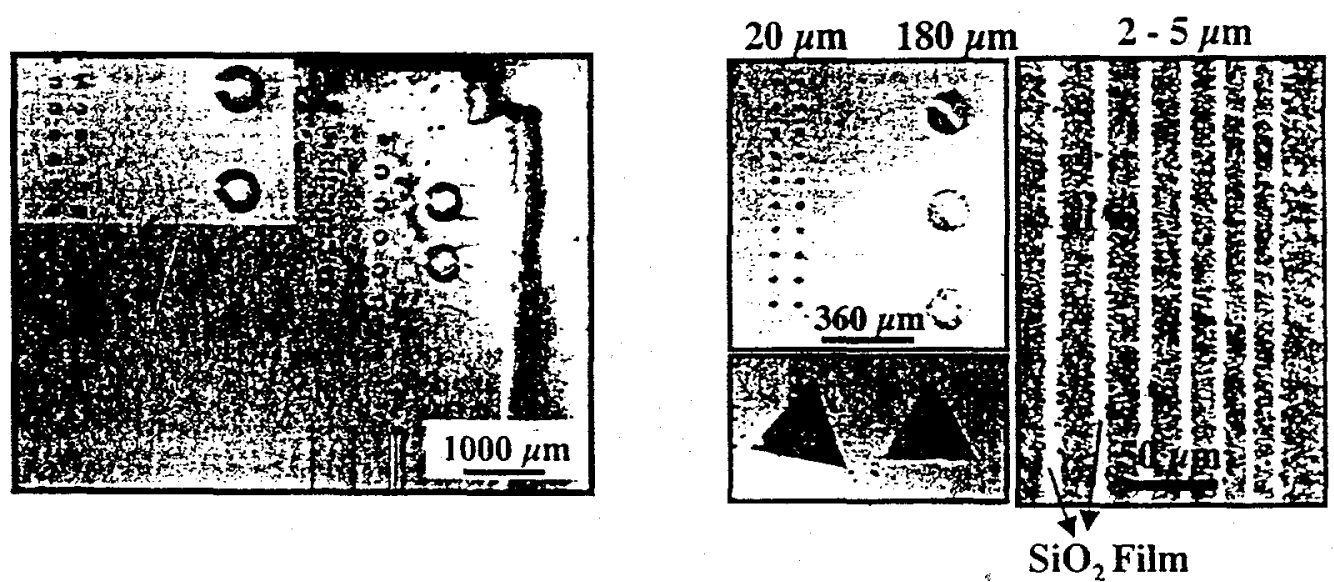

Figure 2. Left: The optical image of a plan-view of the resulting patterned surface after dipcoating in water/propylene glycol/ethanol solution. Right: SEM images of patterned mesoporous silica thin films in different features.

Instead of using alcohol, water, and propylene glycol, a sol containing water, ethanol, silicate and surfactant prepared as described previously was used to prepare a patterned silica mesostructure. Figure 2 shows the corresponding patterned features including circles and stripes of different dimensions. Surfactant templating establishes the secondary ordering and length of scale within the patterned macrostructure. The length scale of the silica mesostructure is tunable by using different sized surfactants, CTAB, Brij-56 and P123 for the pore sizes to be $2 \mathrm{~nm}$, $2.5 \mathrm{~nm}$, and $7 \mathrm{~nm}$ respectfully $[4,9]$.

In addition to pure silica frameworks, the whole patterning process may be extended easily to create patterned functional organo silicate mesostructures. Amine-terminated surfaces 
can be further modified readily using standard organic reactions, e.g., reaction with active esters, activated carboxylic acids, or isothiocyanates.
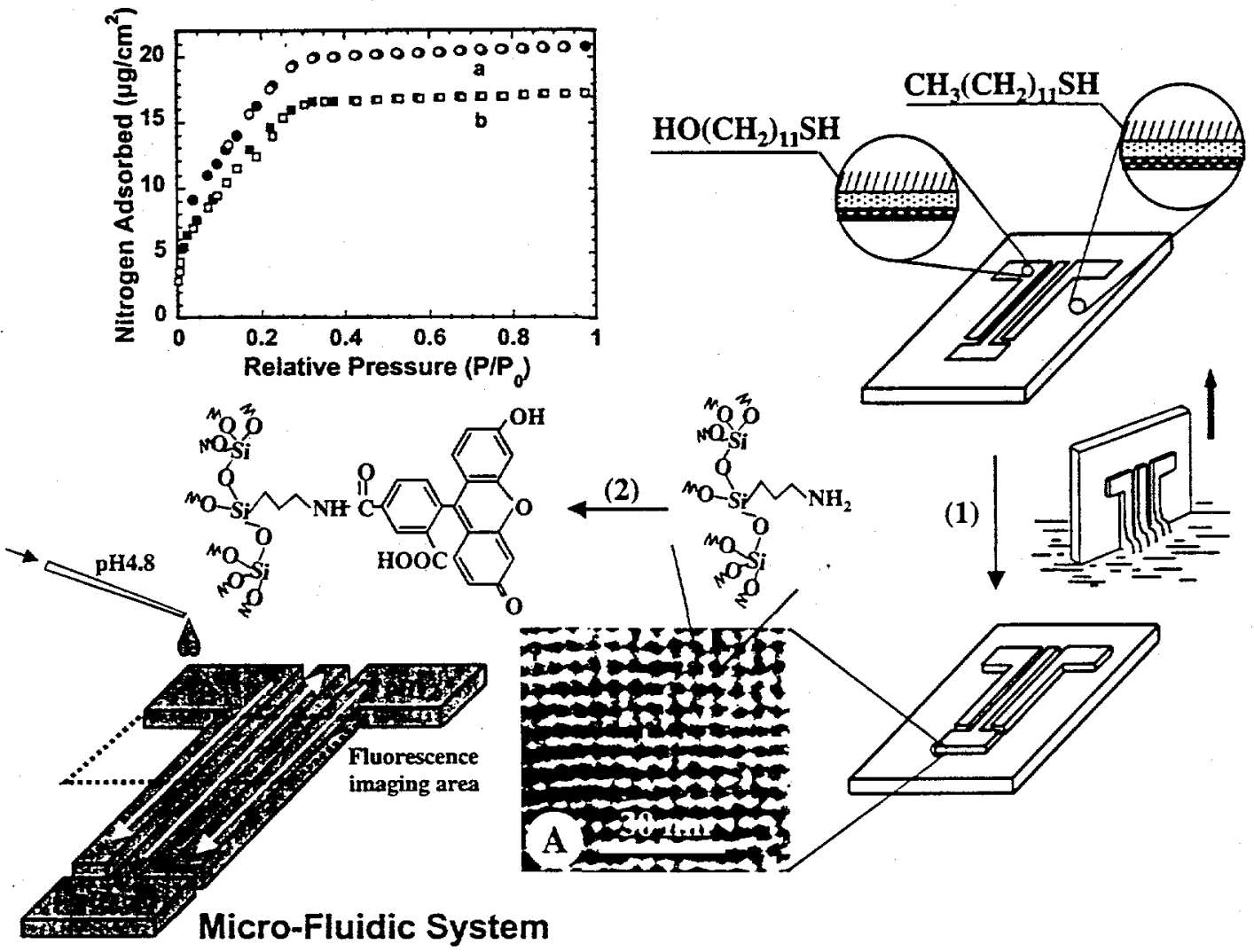

Figure 3 Scheme of formation of patterned functional mesoporous silica thin film containing $\mathrm{pH}$ sensitive dye. (1) dip-coating with hybrid sol containing amine propoyl groups. (2) conjugation reaction with $\mathrm{pH}$ sensitive dye molecules.

In this report, amine-terminated pore surfaces were derived by reaction with an active ester of 5-(and-6)-carboxyfluorescein, succinimidyl ester (5(6)-FAM, SE) which is $\mathrm{pH}$ sensitive. The conjugation reaction between amine-groups and 5(6)-FAM, SE was accomplished by immersing the patterned amine-modified mesoporous thin film into $10 \mathrm{mg} / \mathrm{ml} 5(6)$-FAM, SE solution in dimethylsulfoxide (DMSO) for 4 hours. After reaction the film was copiously washed in DMSO, and dried under a nitrogen stream. We used a micropipet to introduce droplets of $\mathrm{pH}$ solutions with different $\mathrm{pH}$ onto each stripe, then took a fluorescence image. The TEM image in Figure 3 shows uniform continuous FCC cubic mesophase of the patterned amine derived film as well as the nitrogen sorption isotherms of the corresponding amine derived mesoporous silica films deposited on SAW substrates before and after the conjugation reaction with 5(6)-FAM, SE. The reduction in film porosity after dye conjugation reflects the volume occupied by the attached dye moieties. Figure 4 demonstrates the monitoring of the $\mathrm{pH}$ of fluids introduced at arbitrary locations and transported by capillary flow into the imaging cell using the corresponding patterned, functional arrays. Figure 4 a shows the fluorescent image of an array contacted with three different aqueous solutions prepared at $\mathrm{pH} 4.8,7.7$, and 12.0. Figure $4 \mathrm{~b}$ shows the corresponding emission spectra providing a comparison with solution data. In combination, the fluorescent image (Figure $4 \mathrm{a}$ ) and plan-view and cross-sectional TEM images 
(Figures $3 \mathrm{~A}$ and $4.75 \mathrm{c}$ ) of the dye-conjugated film demonstrate the uniformity of macro- and mesoscale features achievable by this evaporation-induced, de-wetting and self-assembly route. In comparison, films formed by nucleation and growth of thin film mesophases on patterned SAMs have been observed to have heterogeneous, globular morphologies. [10]
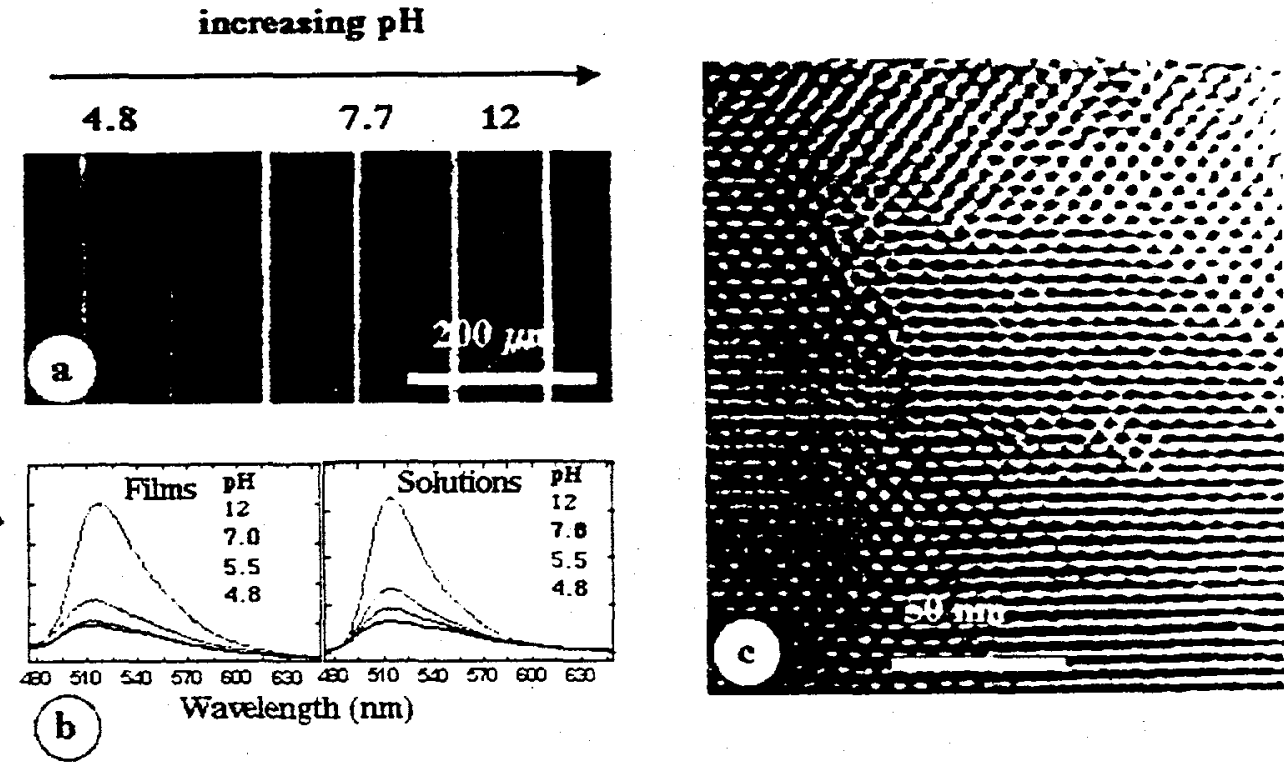

Figure 4. Patterned pH-sensitive fluid system. (a) Fluorescence image of three adjacent 5,6FAM, SE-conjugated pore channel net work after introduction of aqueous solutions prepared at $4.8,7.7,12.0$. (b). Fluorescence spectra of the films exposure to aqueous solutions of pH 4.8, $7.7,12.0$ and comparison with the spectra of $0.1 \mathrm{mM}$ dye in the same $\mathrm{pH}$ solutions. (c) TEM image of corresponding silica mesophase in (a).

\section{SUMMARY}

We combined evaporation-induced (silica/surfactant) self-assembly EISA with dipcoating on micro-contact printed substrates to form patterned arrays in seconds. In addition, by co-condensation of tetrafunctional silanes $\left(\mathrm{Si}(\mathrm{OR})_{4}\right)$ with tri-functional organosilanes $\left((\mathrm{RO})_{3} \mathrm{Si}\left(\mathrm{CH}_{2}\right)_{3} \mathrm{NH}_{2}\right)$, we have selectively derived the silica framework with functional amine ligands. The resulting materials exhibit form and function on multiple length scales: on the molecular scale, functional organic moieties are positioned on pore surfaces, on the mesoscale, mono-sized pores are organized into 1-, 2-, or 3-dimensional networks, providing size-selective accessibility from the gas or liquid phase, and on the macroscale, 2-dimensional arrays and fluidic or photonic systems may be defined.

\section{ACKNOWLEDGMENTS}

This work was supported by the US DOE Basic Energy Sciences Program, the SNL LDRD Program, and the ARPA Bio-Weapons Defense Program. TEM investigations were performed in the Department of Earth and Planetary Sciences at the University of New Mexico. Sandia National Laboratory is a multiprogram laboratory operated by Sandia Corporation, a Lockheed-Martin Company, for the U.S. DOE under Contract DE-AC04-94AL85000.

\section{REFERENCES}

[1] H. Yang, N. Coombs, G. A. Ozin, Nature 386 (1997) 692-695. 
[2] M. Trau, N. Yao, E. Kim, Y. Xia, G. M. Whitesides, I. A. Aksay, Nature 390 (1997) 674 676.

[3] P. D. Yang, T. Deng, D. Y. Zhao, P. Y. Feng, D. Pine, B. F. Chmelka, G. M. Whitesides, G. D. Stucky, Science 282 (1998) 2244-2246.

[4] Y. F. Lu, R. Ganguli, C. A. Drewien, M. T. Anderson, C. J. Brinker, W. L. Gong, Y. X. Guo, H. Soyez, B. Dunn, M. H. Huang, J. I. Zink, Nature 389 (1997) 364-368.

[5] Y. F. Lu, H. Y. Fan, A. Stump, T. L. Ward, T. Rieker, C. J. Brinker, Nature 398 (1999) 223-226.

[6] H. Y. Fan, Y. F. Lu, A. Stump, S. T. Reed, T. Baer, R. Schunk, V. Perez-Luna, G. P. Lope, C. J. Brinker, Nature in press .

[7] Y. W. xia, GM, Angew. Chem. Int. ED. 37 (1998) 550-575.

[8] Y. Xia, J. Rogers, K. Paul, G. Whitesides, Chem. Rev. 99 (1999) 1823-1848.

[9] D. Y. Zhao, Q. S. Huo, J. L. Feng, B. F. Chmelka, G. D. Stucky, Journal of the American Chemical Society 120 (1998) 6024-6036.

[10] H. Yang, A. Kuperman, N. Coombs, S. Mamicheafara, G. A. Ozin, Nature 379 (1996) 703-705. 